\title{
Workplace Mobbing and the Role of Human Resources Management
}

http://doi.org/10.21272/bel.4(1).17-34.2020

Bahaudin G. Mujtaba, D.B.A., ORCID: https://orcid.org/0000-0003-1615-3100

Professor, Huizenga College of Business and Entrepreneurship, Nova Southeastern University, Fort Lauderdale, Florida, USA

Tipakorn Senathip, ORCID: https://orcid.org/0000-0002-0943-2331

PhD Candidate, Faculty of Public Administration, Ramkhamhaeng University, Bangkok, Thailand

\begin{abstract}
Workplace mobbing and bullying are the most pressing and urgent problems which employees, managers and executives of most businesses can face in their day-to-day activities. The HR managers are responsible for the effectiveness of the processes in the workplace management and for protecting employees from unfair harassment and humiliation. The systematization of literary sources enabled us to make conclusions that the most common forms of workplace mobbing include the spreading of malicious gossip aimed at ridiculing and bullying the victim in a department or organization. It is quite often that a gossip is a malicious tool for distorting personal information that has nothing to do with the victim's professional competence. In an extreme case, such humiliations may be distributed beyond the office or scope of the employee's activity. The purpose of the research is to investigate various forms of workplace mobbing as well as its impact on employees, their ability to work in a team, and their effective operation in the company. The article substantiates the role of the HR department in controlling workplace mobbing, the primary function of which is to support the organization's ability to always improve its work efficiency. Given their job responsibilities, HR managers should focus on the legal, ethical, and socially responsible aspects of the company on the implementation of the policy, which forms team relationships due to the principles of mutual respect and dignity under conditions of an inclusive work environment. Besides, managers can take measures to identify, prevent, and effectively resolve daily differences and conflicts promptly. The purpose of these activities is to help employees behave properly, rationally, and professionally, objectively adhering to policies and instructions, thereby creating a supportive workplace environment. The results of the research can be useful for HR managers to make sure all employees can work in a safe and healthy work environment.
\end{abstract}

Keywords: workplace mobbing, bullying, harassment, HR manager, stonewalling, violence.

JEL Classification: D73, L51, M31, I32.

This work is licensed under a Creative Commons Attribution 4.0 International License

Cite as: Mujtaba, B. G., Senathip, T. (2020). Workplace Mobbing and the Role of Human Resources Management. Business Ethics and Leadership, 4(1), 17-34. http://doi.org/10.21272/bel.4(1).17-34.2020.

(C) The Authors, 2020. This article is published with open access at Sumy State University.

\section{Introduction}

Workplace mobbing is the act of bullying others in the work environment; and, such actions are negative, continuous, and tend to intensify over time (Ågotnes, Einarsen, Hetland, \& Skogstad, 2018). Mobbing is not a conflict that occurs in a single incidence, and it can have many forms and types (see Figure 1). Mobbing and workplace bullying can include professional, emotional, verbal, and physical abuses coming in downward, upward, inward, and horizontal forms. Downward mobbing or bullying is when powerful persons of authority, such as managers and supervisor, are using the power the organization has bestowed upon them, to exert their position power over their employees in a negative or intimidating manner (Vandekerckhove \& Commers, 2003). There are also situations where a group of employees band together to go against their boss or superior, and this is considered upward bullying. In certain industries, such as education or even healthcare, bullying can be inward, initiated by students, customers, clients, vendors, patients, or even the patient's families, as they develop a relationship over time and the employee may feel helpless as the patient exudes power over them. Horizontal bullying is a case when a group of employees working together harasses another co-worker, and neither has formal power over each other (De Cieri, Sheehan, Donohue, Shea, \& Cooper, 2019). 
ABUSE Types

4- Physical

3- Verbal

2- Emotional

- Bullying

- Harassing

- Humiliating

- Excluding

- Stonewalling

1- Professional

- Gossip

- Slander

- Intimidation

- Disrespect

- Rudeness

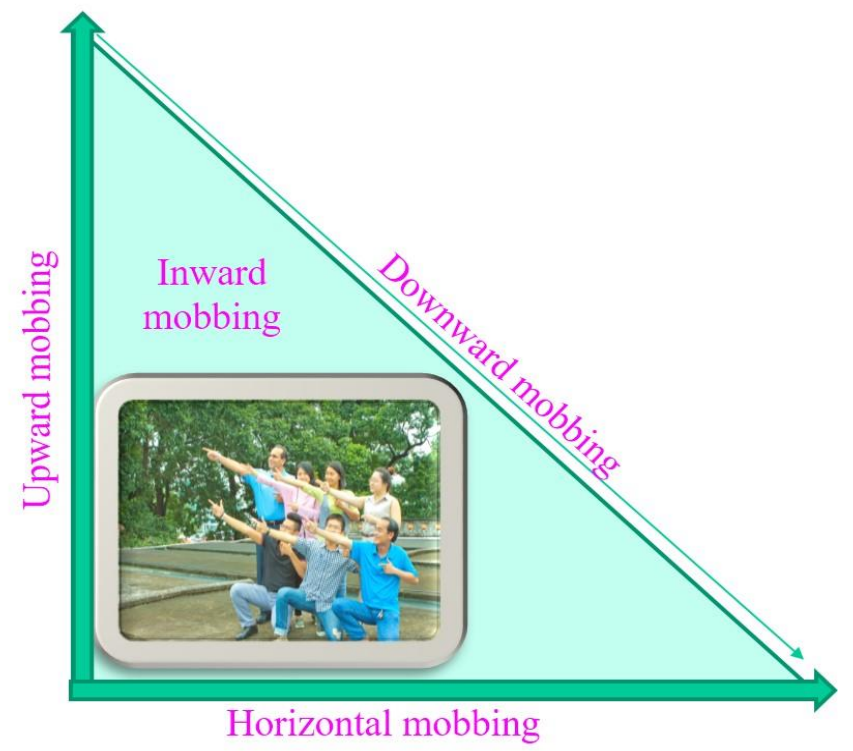

Figure 1. Mobbing Behavior Types and Forms

Source: Author's own creation based on Vandekerckhove \& Commers, 2003; De Cieri, Sheehan, Donohue, Shea, \& Cooper, 2019

While workplace mobbing can be very stressful for the victim as well as HR professionals, managers, and other employees alike, there are some best practices and procedures which must be followed to make the workplace fair and just for all parties involved, especially in the mind of the worker that believes he/she is a victim of workplace mobbing. When you are working and serving as managers or HR professionals, sooner or later you will face the challenge of having to deal with workplace mobbing. Managers must always behave rationally and professionally by objectively following relevant policies and guidelines to make sure the workplace is a good environment for everyone. Therefore, it is best that you are prepared for such an event by thinking about best practices and good policies for dealing with workplace mobbing (bullying).

In this article, we discuss some of the literature and thoughts for effective management of workplace mobbing/bullying. We focus on discussing some of the following questions and topics:

1. What is workplace mobbing? Is it increasing or decreasing in the modern workplace?

2. Examples and causes of workplace mobbing.

3. The impact of workplace mobbing on the employees, departments and the company.

4. The role or responsibility of immediate managers and HR professionals in dealing with workplace mobbing.

5. Best practices and policy recommendations for "effectively" dealing with workplace mobbing.

\section{Literature Review}

Heinz Leymann, a Swedish psychiatrist, introduced the term "mobbing" to denote a specific form of bullying against employees. He insisted that workplace mobbing involves both hostile and unethical communications directed by one or more individuals towards a person who is forced into a helpless and defenseless position due to mobbing activities (Zachariadou 2017). Workplace mobbing can be remembered through its root-word "bullying," and encompasses actions that are collectively coordinated by members of a group toward a specific target. Workplace mobbing involves groups of people targeting a subordinate or coworker for humiliation, aggression, and isolation. Sadly, workplace bullying and mobbing cases are prevalent in many companies around the world, which imposes undue emotional distress on employees of ranks (Cavico, Mujtaba, Lawrence, and Muffler, 2018). Mobbing exists worldwide, with 10-15\% of American workers considering themselves as victims of bullying (De Cieri, Sheehan, Donohue, Shea, \& Cooper, 2019).

Workplace mobbing is increasing in the United States and other countries. In Australia, calls about workplace bullying had increased by 70 percent in three years (Henshaw, 2019). Today, reports show a workplacemobbing rate of nearly 50\% in the US, $4 \%$ in Italy, and 5-10\% in Europe (Maran, 2018). We know that workplace bullying is harmful to the organizational environment; and research has shown that the tendency is rising with at least $30 \%$ of bullying considered to be mobbing (Henshaw, 2018). In the United States, 
approximately 1 in 3 employees are bullied at their jobs, with women being the most common target (Fader, 2019). Another survey (by workplacebullying.com) found that 60.3 million Americans have suffered from workplace mobbing (Peterson, 2019). The survey shows that $70 \%$ of bullies are male and $30 \%$ female and that the over $60 \%$ of the targets are female. About $61 \%$ of the bullying comes from bosses or people in positions of power, while $33 \%$ comes from coworkers. In addition, the minority group that has the highest victims of mobbing happens to be Hispanics. Recently, a 2019 Monster.com survey found that nearly $94 \%$ out of 2081 employees said they had been bullied in the workplace (Robinson, 2019).

According to a study by Sungwan, Deoisres, and Chaimongkol (2017) conducted in Thailand, workplace bullying is related to burnout, low job satisfaction, and early leaving the nursing profession. Their study focused on Thai nurses and emphasized that a negative workplace affects the personal and emotional lives of newcomers, and it may contribute to an inability to recruit more qualified and talented nurses into the profession. New Thai nurses perceived workplace bullying from their seniors as being a process of adjusting to the organization's culture. They concluded, "A more complex and stressful nursing environment was more likely to lead to workplace bullying" in Thailand (Sungwan, Deoisres, and Chaimongkol, 2017: 106). The 67 new nurses reported some form of bullying in the past six months, and 73.13\% of them indicated that a colleague was the perpetrator. The underlying reasons or causes of workplace bullying among the Thai nurses may be related to the characteristics of nursing practice and the work environment, which is intense and stressful.

Workplace mobbing often results in negative feelings and outcomes for the people involved as well as the company (Baillien, Camps, Van den Broeck, Stouten, Godderis, Sercu, \& De Witte, 2016). The behaviors involved may include gossip, verbal abuse, or ostracizing, and sometimes more physically harmful actions like aggression and violence, all of which can cause psychological trauma to the victims and even outside observers (Baillien, Camps, Van den Broeck, Stouten, Godderis, Sercu, \& De Witte, 2016). Sadly, research shows that one in two workers have witnessed some form of bullying in the workplace but have done nothing about it. Moreover, for every case reported, 8 to 20 cases of workplace mobbing go unreported; so the actual incidences of group bullying in today's organizations might be much higher.

Workplace mobbing is a malicious attempt to discredit or even force a person out of the department through psychological terror, unjustified accusations, humiliation, general harassment, and persistent emotional abuse (Davenport, Distler Schwartz \& Pursell Elliott, 1999; Leymann, 1996; Westhues, 2002). Workplace mobbing is far worse when the terrorizing employees campaign to enlist the assistance of coworkers who also participate to intimidate, humiliate, and harass an employee (Petersen, 2019). There are some differences between mobbing and bullying as "Mobbing always includes organizational dynamics and involvement, whereas bullying does not" (Duffy \& Sperry, 2012). What characterizes and differentiates mobbing from bullying is the collective nature of the aggression by two or more individuals, the agreed-upon, and implied or unspoken collaboration that comes across to the target as genuine conspiracy (Morrison Kenney, 2014). However, as Shelton (2011: 5) explains, "It appears both terms are being used somewhat interchangeably" in the literature to describe various acts of workplace mobbing.

According to the Workplace Bullying Institute (2019), bullying can be any abusive behavior that takes the method of verbal abuse, threats, humiliation, intimidation, or interference that prevents the target from getting work done in a timely manner. In most instances when one mentions the word "bullying," people tend to think of someone that appears tough in demeanor while pushing another, yelling or even being angry or aggressive, but workplace mobbing tends to take place silently and collectively. Kasi Mclaughlin (2014) states workplace mobbing usually comes in the form of exhibiting unwarranted criticism or intimidation, blaming someone without factual justification, unfairly singling someone out, or spreading rumors. According to the Workplace Bullying Institute (WBI, 2007) survey, 45\% of targeted individuals suffer stress-related health problems.

Over the past decade, especially since the economic recession in the United States during 2007, there has been a significant increase in workplace bullying and mobbing incidents. Workplace mobbing or bullying has doubled in the last decade as data shows that at least 1 in 10 employees will experience some forms of workplace mobbing and harassment (Hirsch, 2010). Research also shows that almost 75 percent of people surveyed mentioned that they had been impacted by workplace mobbing (Comaford, 2016).

Bullies exist in all age categories, all races, and both genders; no one is immune from being the target of a bully at some point in their lives. Even the bullies themselves are likely to eventually be bullied by a bigger and dumber bully. The workplace is no exception. There are office cliques, overzealous workers vying for 
power; and there are always people willing to follow the lead of a troublemaker. Their target can be anyone, but it is most often a top performer or someone who is perceived to be a threat to an individual's job due to their high performance or good work ethic. This bullying is workplace mobbing, or the intentional efforts of a person or persons to ostracize one top performing employee with the goal of forcing them out (Murrell, 2018).

A study of factory line workers in the 1940's showed that group of workers collectively agreed and committed to only perform at a certain level of performance; but when a few top performer's decided to perform their job duties to their fullest potential they were harassed and referred to as "rate busters" because they would not conform to peer pressure (Murrell 2018).

Workplace mobbing is related to terms like "systematic soldiering", "group bullying" or "bullying on steroids". In the modern workplace, workplace mobbing can involve one or more employees ganging up to target or bully a coworker through isolation, humiliation, and aggression. The impact of workplace mobbing can be destructive on the business and it can be very serious legally as it can be seen as harassment. As such, HR professionals and managers should be aware of workplace mobbing and take proactive and reactive steps to foster a healthy work environment for all employees.

Over 100 years ago, the father of scientific management, Frederick Taylor, explained that systematic soldiering resulted from group pressures for individuals to conform to output norms set by the work group. Frederick Taylor felt he could overcome systematic soldiering and improve the situation if workers knew that the production standards were established by a study of the job, rather than by historical data, and if incentives could be provided.

Extreme forms of peer pressure and systematic soldiering can cause much undue conflict in the workplace. Conflicts among colleagues and coworkers are inevitable, and healthy conflict can be beneficial to creativity and productivity. However, sinister conflicts using mobbing toward specific individuals can amount to psychological terrorism and distressful anxiety for the victim. Bullying and mobbing may occur more often in firms and departments that do not regularly and fairly evaluate performance and individual behavior. It is said,

When a company tolerates an employee, who is unpleasant to work with, does not follow office policies or who fails to complete his or her work, other employees may become resentful. This can lead to the mobbing of the underperforming or disliked employee. Unfortunately, office morale has likely decreased significantly by the time workers take matters into their own hands (Petersen, 2019: 18).

As such, managers and human resources professionals must effectively deal with employee bullying and "workplace mobbing". Some employees who are bullied tend to resort to extreme violence. You may have seen on the news the very unfortunate case of an unhappy, depressed, and/or disgruntled employee, who had just submitted his resignation that was involved in a mass shooting in Virginia Beach. On May 31, 2019 in Virginia Beach Municipal Center, a long-time city employee (utility engineer/project manager), by the name of DeWayne Craddock, was either upset, depressed, and/or unhappy with some element of his job or possibly disheartened due to workplace mobbing and/or other circumstances, ended up killing 12 people and injured 5 others in the public utility building.

Another sad situation was just three months earlier in the case of Gary Martin (during February 15, 2019) when he took a gun with him to work and killed 5 superiors and colleagues while injuring 6 others in his place of employment in Aurora, Illinois. Apparently, he had become aware that he was going to be fired, perceived that everyone was against him, and choose to take a gun with him to work that day and became violent during the termination meeting.

Human resource management is about the creation and implementation of the policies, practices, and systems that collectively influence and guide employees' behaviors, attitude and performance toward a professional and safe workplace for all. Since the modern workforce is very diverse, global human resources management skills related to inclusion are important for business professionals in all countries and organizations (Kyaw, Harland and Mujtaba, 2017). Human resources departments introduce and provide structure to any organization's culture and day-to-day norms (Mujtaba, 2010). Human resources professionals are also usually responsible for administering and implementing policies for the organization. As such, HR professionals and managers must know when to intervene during certain situations on the job. Keeping employees motivated and positive enhances performance levels and creates a healthy work environment for everyone. Employee engagement and empowerment are some of the key factors that business professionals and managers should pay close attention to as it is critical for sustainable success. 


\section{Workplace Mobbing}

Workplace mobbing is a form of group bullying that isolates an individual and causes humiliation and psychological abuse, which not only affects a worker's productivity, but it also has an effect on an employee's overall health. Mobbing can result in increased stress levels, anxiety, low work performance, and resignations that lead to difficulty in recruiting (Georgakopoulos \& Kelly, 2017).

Noe, Hollenbeck, Gerhart, and Wright mention that workplace bullying is a repeated health-harming mistreatment by one or more perpetrators at work that takes the form of verbal abuse and offensive conduct that is threatening, humiliating or intimidating to the point where it prevents work from being done (2018). Other experts state that:

Workplace mobbing is nonsexual harassment of a coworker by a group of members of an organization for the purpose of removing the targeted individual(s) from the organization or at least a particular unit of the organization. Mobbing involves individual, group, and organizational dynamics. It predictably results in the humiliation, devaluation, discrediting, and degradation; loss of professional reputation; and, often, removal of the victim from the organization through termination, extended medical leave, or quitting (Duffy \& Sperry, 2012: 52).

A 2012 survey found that 35\% of respondents reported being bullied by co-workers on the job (Noe, Hollenbeck, Gerhart \& Wright, 2018). However, according to Comaford (2016), almost 75\% of employees surveyed had been affected by workplace bullying, whether as a target or a witness. Overall, workplace mobbing seems to be increasing in the modern workplace. Workplace mobbing is a serious form of harassment that, if not addressed or mitigated effectively by human resources professional and managers, can negatively affect both the victim and the organization.

Bullying is a less severe and encompassing form of abuse than mobbing (Duffy \& Sperry, 2012). Workplace mobbing is a more extreme form of bullying. Colleagues and coworkers induce terror onto a targeted employee, which might cause much undue stress and eventually he or she might leave the organization. Targets can be employees who are educated, those who challenge the status quo and are outspoken teammates; mobbing victims are likely to be women, middle aged, and often a minority member of a protected group (Henshaw, 2018: 2). Victims can be ridiculed and humiliated at such an intense level that this can leave psychological damage that affects them at work and into their everyday lives. The bullies, who are likely feeling threatened by the employee in some way, will recruit others to conduct these ostracizing acts and can even force others who do not participate in the mobbing to not socialize with the individual. Research shows that "at least 30 percent of bullying is mobbing - and the tendency is rising", leaving human resources professionals to find solutions to stop these actions from continuing at the workplace (Henshaw, 2018: 6). In this paper, we focus mostly on workplace mobbing actions which includes bullying; however, as can be seen in Table 1, other terminologies has also been used by researchers to describe various related activities which can be part of workplace mobbing.

Table 1. Terms and Definitions related to "Mobbing"

\begin{tabular}{|l|l|}
\hline \multicolumn{1}{|c|}{ Terms } & \multicolumn{1}{c|}{ Definitions } \\
\hline Harassment & $\begin{array}{l}\text { - Repeated and persistent attempts by a person to torment, wear down, frustrate, or get a reaction from } \\
\text { another person; it is treatment which persistently provokes, pressures, frightens, intimidates or } \\
\text { otherwise cause discomfort in another person. } \\
\text { - Situations where a person is exposed repeatedly and over time to negative action on the part of one } \\
\text { or more persons. } \\
\text { Repeated activities, with the aim of bringing mental (but sometimes also physical) pain, and directed } \\
\text { towards one or more individual who, for one reason or another, are not able to defend themselves. }\end{array}$ \\
\hline Scapegoating & $\begin{array}{l}\text { One or more persons who during a period of time are exposed to repeated, negative actions from one } \\
\text { or more other individuals. }\end{array}$ \\
\hline Mobbing & $\begin{array}{l}\text { One or more person's repeated and enduring negative reactions and conducts targeted at one or more } \\
\text { person of their work group. }\end{array}$ \\
\hline $\begin{array}{l}\text { Mobbing/Psychological } \\
\text { terror }\end{array}$ & $\begin{array}{l}\text { Hostile and unethical communication that is directed in a systematic way by one or more persons, } \\
\text { mainly towards one targeted individual. }\end{array}$ \\
\hline $\begin{array}{l}\text { Health endangering } \\
\text { leadership }\end{array}$ & $\begin{array}{l}\text { Continuous humiliating and harassing acts of long duration conducted by a superior and expressed } \\
\text { overtly or covertly. }\end{array}$ \\
\hline Petty tyranny & $\begin{array}{l}\text { A leader who lords his power over others through arbitrariness and self-aggrandizement, the belittling } \\
\text { of subordinates, showing lack of consideration, using a forcing style of conflict resolution, discoursing } \\
\text { initiative and the use of non-contingent punishment. }\end{array}$ \\
\hline Bullying & \begin{tabular}{l} 
Persistent criticism and personal abuse in public or private, which humiliates and demeans a person. \\
\hline
\end{tabular}
\end{tabular}

Source: Shelton, 2011: 6 


\section{Methodology}

In this paper, first we conducted a thorough review of existing literature regarding workplace mobbing and bullying practices while also planning to conduct a qualitative but informal interview of working professionals about their actual experiences. Consequently, second, we informally interviewed five working professionals to determine how prevalent bullying and mobbing techniques have been in the modern workplace as per their observations over the past ten years in the South Florida region of the United States of America. Because of the literature review and the accumulated experiences, under the findings and results section, we provide a discussion of the mobbing techniques and its causes, the impact of workplace mobbing, and some best practices for human resources professionals and managers so they can effectively prevent such negative incidents from taking place in their departments and organizations.

\section{Findings and Results}

\section{Mobbing Techniques}

Workplace mobbing is most likely to occur in certain competitive atmospheres and industries where employees and managers face increased financial pressures (Henshaw, 2018). In these occupations, the employees are usually competitive, and money driven, often forming a hostile environment for co-workers. Workplace mobbing behavior has also been observed in bureaucratic organizations. Sadly, most of these workplace mobbing interactions become defined as a "personality conflict" by human resource departments and are left to escalate (Henshaw, 2018) rather than being seen as bullying behaviors.

Workplace mobbing actions include discrediting one's work and magnifying miniscule mistakes, leaving victims out of important meetings or events, and spreading rumors about their personal or professional life (Segal, 2017). These events could seem unimportant, but they can negatively affect one's emotional wellbeing. Regardless of industry or atmosphere, as mentioned before, mobbing tactics can include such acts as verbal aggression, stonewalling, exclusion, physical aggression, gossip, and slander. These tactics can vary in severity, which causes damage to an individual emotionally and physically.

Verbal aggression can be orally intimidating and threatening statements, which include sexual harassment. Sexual harassment is the making of unwelcomed and inappropriate sexual remarks or physical advances in the workplace on a repeated basis.

Stonewalling is when victims are being excluded from work activities, task completion, and planning events. This means their suggestions or projects are being ignored by coworkers or even supervisors who are part of the mobbing process. In such cases, any sort of feedback or updates to the targeted employee is completely ignored. A coworker could say they "accidentally" forgot to include the victim in an important e-mail or "forgot" to invite them to an important meeting. In one case, a female employee for Deutche Bank in London was a victim of workplace mobbing where her co-workers stonewalled her. These colleagues removed her name from circulation lists; they even hid her mail, removed papers from her desk, laughed in her face, blew raspberries at her and made unprofessional statements such as, "You stink" (Saltmarsh, 2007). This treatment created a hardship for her, and her employment with the company was eventually terminated. In this particular case not only did the victim face stonewalling as a form of mobbing, but she also endured exclusion and verbal aggression making it difficult for her to focus on her immediate tasks and her employment was eventually terminated, which is a lose-lose outcome both for her and the company.

Physical aggression and abuse can occur when employees take an individual away from the workplace to isolate and threaten them, push a person, point to a person with implications of harm, and to persuade others to participate in a particular activity that hurts another by force. Each individual handles workplace mobbing differently, and it is essential to be aware of proper responses and actions when being targeted.

Gossip and slander are other popular workplace mobbing techniques. The leader may start malicious gossip specifically designed to humiliate and undermine the victim (Petersen, 2019). It should be noted that some forms of gossip can be legally considered as slander, libel, or defamation of character (Cavico and Mujtaba, 2014).

Sometimes after all of these tactics, workplace mobbing can escalate to physical aggression and blatant conflicts. It is rare for workplace mobbing leaders to use physical aggression since they know that such incidents can be observed, recorded and witnessed by others. Because people can face civil and criminal charges in the court of law, most workers and harassers do not use physical and verbal aggression; but if the perpetrator feels there will not be any repercussions and that they can get away with it, they may try to use it. 
Exclusion and condescension are other serious methods of workplace mobbing. Exclusion can be done in many ways. An example is by excluding a coworker from informal interactions in the breakroom. Exclusion is a form of mobbing tactic that can facilitate and administer workplace bullying. For example, intentionally and collectively deciding to leave the target employee out of a thread of emails or excluding him/her from a special meeting or group celebration taking place in the department are examples of things that can take place when mobbing is occurring. Such exclusive techniques can make the targeted employee feel isolated, disengaged, frustrated, and dissatisfied and, at times, leading to the "revolving door syndrome" for some groups of diverse employees.

Condescension is a powerful tool of manipulation. A colleague, manager, or any workplace personnel that humiliates, condescends, or speaks down to another coworker is taking part in workplace mobbing. Condescension can be done privately or publicly in a meeting.

Overall, we can say that there are many forms of workplace mobbing which exists in various types such as downward, horizontal, inward, and upward. As mentioned before, downward mobbing is usually initiated by a boss or authority figure onto a subordinate; horizontal mobbing is between peers, inward mobbing can come from customers and clients, and upward mobbing occurs when a group of workers attempts to bully a superior.

\section{Causes of Workplace Mobbing}

Most forms of workplace mobbing come about because of a real or perceived imbalance of power between two or more individuals (De Cieri et al., 2019). Bullying comes from insecure bosses that see it as an opportunity to build their own self-esteem, while many others develop because of jealousy, annoyance, or a perception that the victim is a threat in some way to them within the organization (Wall, Smith, \& Nodoushani, 2018). Often, bullies attempt to exploit some difference between themselves and the victim, whether it be based on gender, race, age, disability, religion, body size, or formal power within the organization (De Cieri et al., 2019).

One study (Vartia, 1996: 207) showed that $63 \%$ of mobbing victims surveyed stated that jealousy was the cause of mobbing. Feelings of inadequacy and/or feeling threatened by individuals more competent or creative creates an environment of mob mentality (Segal, 2010). Politically motivated employees may also wish to push out whistleblowers or simply maintain the status quo (Petersen, 2019). Workplace mobbing is likely to occur in bureaucratic workplaces that have strong union or seniority systems, such as tenured college/school faculty, hospitals, and factories, where the hierarchy or seniority plays a role in who is promoted or can utilize privileges (Segal, 2010). Individuals that are not in the tenured or senior roles may feel the need to undermine and bully the senior individuals in order to "paint them in a bad light" and increase their own chances for success.

As reported by the Workplace Bullying Institute (2019), causes of workplace mobbing include bullies being threatened by the target's technical skills, and when the target is not a political game player, bully is threatened by targets popularity with others, and targets are noticed by higher ups; therefore, the bully experiences jealousy. Bullies tend to prefer the individuals that tend to have low self-esteem and that are vulnerable. They know not to mess with someone that will retaliate back. Bullies are often afraid of seeing their own shortcomings coming to light, therefore opt out to bully the targets they feel threatened by and use them as scapegoats.

Maintaining the status quo, driving out whistle blowers, pushing out difficult or underperforming employees, and other such personal reasons, can be some of the common causes of workplace mobbing. Skilled employees seem to be one of the main reasons for workplace mobbing. Skilled employees receive positive recognition for their hard work, which at times causes others to feel inferior compared to them. Another reason is the target may be well known or liked in the department. We know that bullies do not like it when another person can threaten their popularity or social status. Another common reason for workplace mobbing is that the target is a very good person and liked by others; they are caring and social. To a workplace bully, these characteristics drain the power they have at work (Gordon, 2019).

Workplace mobbing reasons for group harassment and intimidation can range from envy to getting rid of a troublemaker or whistleblower (Petersen, 2019). Professional jealousy is a common theme for workplace mobbing, and it usually occurs when an individual is more skilled, attractive, and productive than other workers. Jealous individuals begin to bully the victim until their performance declines, or the employee leaves the company. When an individual sees other employees meeting quotas frequently, workplace mobbing can occur. 
Generally, it is against the law to fire someone without having a lawful reason. When an employee is either difficult to work with or is underperforming, workplace mobbing can occur. This technique is sometimes used by managers to pressure an employee to leave the organization voluntarily without having to fire them. Workplace mobbing can also happen because of personal reasons. Individuals can have a bullying personality or take satisfaction in annoying others. If peer employees do not participate in workplace mobbing, they may feel like they could be the next target.

Coworkers who participate in workplace mobbing against a certain individual usually feel threatened in some sort of way by the employee or are emotionally immature (Henshaw, 2018: 7). Mobbing is also more likely to occur in places of employment that are focused on profits or are numbers-driven, such as in sales, where there is a competitive atmosphere. This kind of environment can be toxic, and some managers even encourage or reward bullying behaviors to increase market share, profits, or immediate sales. Some organizations appear to have policies in place that ensure that there is a safe workplace environment; and often label bullying simply as a "personality conflict" which can leave the victim of workplace mobbing with no place to turn, but to leave the organization (Henshaw, 2018: 9).

\section{Examples of Workplace Mobbing}

According to a 2014 survey, 68 percent of cases reported involve women-on-women bullying (Workplace Bullying Institute, 2019). Workplace mobbing can be extremely subtle, for this reason it is important to understand the difference between a coworker that is just having a bad day and one that is a constant bully.

There are many examples of bullying and workplace mobbing; however, the most common cases include some form of gossip, innuendo, isolation, and collectively creating embarrassing or humiliating situations that target an individual. Rumors and gossip are generally used to aid in doubting a victim and making the workplace uncomfortable for them. According to Hamblem (2018), "workplace mobbers" create a harassing atmosphere to make the workplace so uncomfortable that the targeted victim must remove him or herself from the department.

One of the common types, a form of downward bullying, is when a boss or senior colleague gives the employee an excruciating workload designed to strain him/her either physically, mentally, or emotionally (Wall et al., 2018). Because the boss has formal power over them, often with the ability to write negative performance reviews or recommend termination, the employee will make personal sacrifices to complete the work, causing undue stress and emotional trauma on the employee. Generally, workplace-mobbing activities can include not giving credit for work to others who deserve it, discrediting satisfactory work, magnifying minor mistakes, reducing an employee's responsibilities, and leaving individuals out of important meetings. Other actions might include spreading rumors about employee's personal or professional lives, giving individuals unfairly poor evaluations, vandalizing offices or homes, threatening or attempting physical violence, or accusing those targeted of initiating violence (Segal, 2010).

Targets of workplace mobbing can be individuals who are different from the majority of their coworkers, based on their gender, race, religion, sexual orientation, age, physical attributes, or disability (Petersen, 2019). Another type of target can be an individual that works hard, is kind to others, and non-confrontational, which are positive attributes; but a workplace bully disagrees and consequently will target the person. Individuals who are not confident or will not stick up for themselves is another targeted group for workplace mobbing. Some general examples of workplace mobbing include:

$>$ slander, gossip, or spreading rumors;

$>$ disrespect;

$>$ intimidation;

stonewalling;

excluding;

isolating and ignoring;

physical and verbal aggression;

humiliating;

yelling and screaming;

making derogatory, biased, and/or inappropriate jokes; 
setting impossible deadlines that will set up the target for failure;

tampering with the target's personal belongings.

There are many different actions that can be classified as workplace mobbing. For example, coworkers can spread rumors and gossip about the targeted employee that will discredit them (Hamblen, 2018: 4). This misconduct will begin to make the work environment uncomfortable for them. Bullies will orchestrate embarrassing, humiliating, and harassing experiences for the employee that can become so intense that they have to remove themselves from the environment. Victims can also be targeted by being isolated from others to the point where they feel as they do not have anyone they can turn to (Hamblen, 2018: 4). Sexual harassment and discrimination can also be considered workplace mobbing if multiple people are targeting one employee in the same manner.

\section{Effects of Workplace Mobbing}

The impact of workplace mobbing on employees can be serious and will even effect their lives outside of the office. Some employees will even suffer from post-traumatic stress disorder (Segal, 2017). Mobbing in the workplace creates a stressful environment, which is considered worse than other stresses and may cause an employee's attendance to be affected as they may become depressed or not come to work because of the negative and damaging abuses they are receiving (Ågotnes, 2018). Workplace mobbing can label a company in a negative manner; therefore, human resources professionals must take preventive steps.

"High job stress, conflict, and low autonomy are associated with higher levels of workplace bullying. In such an environment, interpersonal conflicts can be a consequence, though undesired and unwanted result. Thus, the work environment may be at least one major reason that fosters workplace bullying" (Sungwan, Deoisres, and Chaimongkol, 2017: 106).

Workplace mobbing can affect the victim's work performance. Victims can be traumatized and may not be able to competently perform their jobs to the best of their ability. Performance issues include lower productivity, inability to work or concentrate and experiencing trouble in decision-making (Gordon, 2019). Workplace mobbing has many impacts on the organization and work culture. Victims or employees that are mobbed or bullied in the workplace, often go through the following five stages: (1) denial and disagreement; (2) anger and aggression; (3) bargaining; (4) depression; and (5) acceptance (Fader, 2019).

Workplace mobbing effects not only the victim, but also coworkers and the organization. Over time, bullying in the workplace can hurt employee morale and damage the reputation of a company. Victims of workplace mobbing have physical and psychological symptoms, which can cause their work performance to suffer. Furthermore, other employees can become fearful of being the next target if workplace mobbing is tolerated. In addition, this fear can lead to excessive anxiety and interferes with job performance, or the employees may decide to leave their current work environment because it is toxic (Petersen, 2019). Companies that tolerate workplace mobbing, bullying, and have a poor workplace culture will lose their best employees. Moreover, a company that does not effectively address mobbing situations can face costly lawsuits.

The acts of workplace mobbing can have repercussions of psychological damage on the victim. These acts can "take away a person's safety in the world, dignity, identity, and belonging and damages his or her mental and physical health", and "the effects also radiate outward toward the target's partner, family, friends, and even community" (Henshaw, 2018: 3). Eventually, persistent mobbing and bullying can lead an employee to leave the organization.

Workplace mobbing "results in the humiliation, devaluation, discrediting, and degradation; loss of professional reputation" and as a result of mobbing, individuals may suffer psychological, career, health losses (Duffy \& Sperry, 2012: 52). In the Duetche Bank example, the victim ended up having a breakdown and was placed on suicide watch only to later slide into a deep depression (Saltmarsh, 2007). The physiological effects of this workplace mobbing prevented her from being able to focus and effectively do her job resulting in her termination.

Although mobbing primarily effects individuals, it also affects an organization as a whole. Organizations that tolerate bullying and negative workplace culture will eventually lose their best employees (Petersen, 2019). In addition to losing employees, the organization may have a hard time attracting new employees. Most professionals would not want to work for an organization that does not discipline employees for participating in such negative workplace mobbing behaviors. Tolerating workplace mobbing, moreover, could result in a lawsuit as federal labor laws protect employees from unfair discrimination and a hostile workplace. 
In summary, aside from psychological implications on employees who may fall victim to workplace mobbing, there are a few other consequences when this behavior occurs. Firstly, people who take part in workplace mobbing are likely to experience internal investigations by their employer and HR department. Depending on the organization, certain disciplinary procedures may exist for mobbing cases. If it is the first time a mobbing case is present within the organization, new policies and procedures may be written and put into place. Secondly, the victim may be able to file a lawsuit against the bullies, which may require the parties involved to reimburse the victim for losses or damages, including lost wages, costs of therapy, and legal costs. In addition, if the victim resigned or was wrongfully terminated due to mobbing, a legal claim might allow them to claim millions of dollars from the company while returning to their previous position before the harassment took place (Hamblen, 2018).

We can summarize that bullying in the workplace may cause victims to suffer from mental anguish and cognitive dissonance. Research has demonstrated that witnesses suffer as much or more emotional trauma as the victims themselves (Wall et al., 2018). Therefore, the department's morale is likely to suffer, and productivity can decline. Overall, the existence of workplace mobbing is detrimental to all facets of the company, its departments, and its employees.

\section{Discussion}

\section{The Role of HR Professionals}

HR professionals need to handle cases of workplace mobbing carefully, methodically, and immediately. Expressing the importance of a "bully-free" workplace is key. Human resource professionals should be ready to help and reduce workplace mobbing. Some best practices for reducing workplace mobbing include making a business case, holding awareness training, establishing a contact for reporting claims, and promptly addressing complaints (McLaughlin, 2014).

Employees who are victims of mobbing will feel understood and more valued knowing that their HR department is committed to providing a safe work environment by not tolerating such unprofessional actions (Gleason, 2017: 3). Training employees on what workplace mobbing is on an annual basis and reminding them which activities, cases, and actions are not tolerated at the workplace can aide in establishing, creating and sustaining a safe work environment for all. Managers and supervisors should also undergo training on how to handle cases of workplace mobbing situations in their department and should have a clear understanding of how to monitor these instances. HR professionals should implement these practices and make sure the workplace culture is an inclusive, healthy and safe work environment for all (Gleason, 2017: 6). Since the impact of workplace mobbing can be devastating for the victims and the organization, managers should take employee behavior and office culture seriously (Petersen, 2019). Human resources professionals play a critical role in building and fostering a positive culture within the department and firm. Organizational culture is built by managers and workers through their day-to-day norms; as well as by how they work, the brand, and the overall reputation of any institution.

Lack of structure, ineffective leadership, and poor human resources practices are factors that can be associated with workplace mobbing. When bullying is present, it seems to grow in its circle of significance to others in the organization because of the effects that bullying imposes, like excessive stress and depression, and the corporate culture that reinforces it (Georgakopoulos \& Kelly, 2017). Although companies continuously promote positive work life balance, conflicts and bullying are sometimes inevitable and can become a serious problem for the victim, witnesses, and the company. Being that workplace mobbing can be related to discrimination and lawsuits, companies should try to enforce anti-bullying policies to tackle and prevent all such forms of bullying (Georgakopoulos \& Kelly, 2017). Managers and leaders realize that continuously monitoring and working to eliminate workplace mobbing is extremely important for a good work environment.

When leaders do not understand the damaging impacts of mobbing, they often ignore it. If a company has effective and ethical leadership, it is more likely that bullying will be discouraged as it is considered legally and ethically intolerable behavior that shows lack of respect and responsibility for others (Appelbaum, Semerjian, \& Mohan, 2012). Companies have the responsibility to make sure that their employees work in a safe environment that is free from bullying. Therefore, to effectively deal with mobbing leaders must develop a culture where mobbing cannot thrive. Polices must be implemented, reviewed periodically, and reinforced against mobbing.

Employees also have a role to play to prevent and manage bullying. Employees must report any incidents of inappropriate behavior so that leadership is aware. In addition to reporting incidents of bullying or 
inappropriate behavior, employees can make sure that they demonstrate positive behaviors and follow the policies set in place to prevent mobbing. Furthermore, human resources professionals have a responsibility to maintain and update bullying policies and processes. As such, everyone in the company must take part in preventing and responding to workplace mobbing. All managers and employees must come together to recognize mobbing, report bullying behavior, and enforce anti-bullying policies to control the negative affect mobbing has on the workplace environment.

Awareness training is beneficial because it thoroughly explains the policies and consequences if they are broken. By holding various training workshops, it will make it clear to all employees that workplace mobbing will not be tolerated in the company. Additionally, addressing these bullying complaints promptly is fundamental. By doing so, it is evident the company takes such claims seriously. Accordingly, it is the responsibility of HR professionals and managers to educate people about bullying and its effects on individuals and the company, embrace anti-bullying legislation, and be sharp enough to notice and curb signs of bullying. Finally, recommendations and best practices include an individual initiative to stop bullying, creating awareness about workplace bullying, and the creation of legislations that condemn bullying.

\section{Recommendations}

Workplace mobbing is present at almost every company; as such, it is essential for management to understand how to stop bullying. Managers and HR professionals need to be on the lookout for workplace mobbing and understand the different types of bullying. Preventing workplace mobbing starts with the culture that is present at the company. Experts recommend establishing core company values that promote collaboration and teamwork over individual competition as this strategy is more likely to reduce the incidence of bullying (FormaSpace, 2017). When company values of inclusion and lack of tolerance for workplace mobbing are presented to each employee and enforced consistently across the organization, eventually it becomes part of the culture.

HR Professionals need to train management about how to deal with workplace mobbing by providing information on its existence and the importance of dealing with the situation immediately and directly. For sustainable leadership and success, organizations should require managers to participate in courses for conflict resolution, and reward leaders who provide positive ways of handling workplace discord before the situation escalates (Ågotnes, 2018; Mujtaba, Senathip and Cavico, 2020).

Although a company may have multiple policies in place to prevent workplace mobbing, it is almost impossible to completely prevent these occurrences. When a case of workplace mobbing is addressed, it is pertinent for a company to address it promptly and seriously. Human resource professionals should be sure to document everything in detail, gather as much information on the event as possible, and directly address the behavior with both the target and the offender (Henshaw, 2018). By effectively dealing with workplace mobbing, HR professionals and managers can lower the chances of repeat events and prevent current cases from worsening, thereby leading to a healthy workplace for all.

Some examples of HR techniques designed to prevent workplace mobbing or disengage bullying are teambuilding exercises where employees are forced to work together outside the office (Noe et al., 2018). Another strategy is the facilitation of collaborative workspaces and assigning formal mentors to new employees, so no one is left feeling alone or inferior to any other co-worker (Murrell 2018). Other best practices that employees who are being targeted against can utilize includes documenting everything in detail, giving yourself space, getting a good recovery team, making self-care a priority, and engaging in meaningful life activities (Henshaw, 2018: 12). Following these practices can ensure that a victim of workplace mobbing will not succumb to psychological damages. Documenting everything in detail, especially for HR purposes, can help an employee guard themselves with proof of mistreatment. As workplace mobbing continues to grow, it is important that both the employee and HR professionals take action to prevent these negative incidents in the workplace.

The human resource department needs to write formal policies for employees to read and understand. These policies need to include specific language with an explicit focus on acts of group bullying or workplace mobbing that target diverse employees (Murell, 2018). Companies need to put a policy of zero-tolerance for workplace mobbing. When a policy is in order, employees must follow the policy, or the consequences must be applied. It is also crucial for companies to have a protocol to methodically and consistently follow through when workplace mobbing is occurring in the company. It should be noted that having an inclusive organizational environment that resist group bullying is necessary to have engaged employees (Murell, 2018). 
Leaders must become aware of signs of workplace mobbing and take appropriate actions. When leaders respond effectively to the mobbing situations it demonstrates integrity and caring to their employees.

Having clear and concise policies for dealing with workplace mobbing is a great start. Having a zero-tolerance towards workplace harassment and enforcing anti-bullying policies can improve the culture within an organization. Clear policies can set the tone for expectations of professional behavior and mitigate any mobbing that could possibly take place. In the case of a zero-tolerance policy, termination of employment would be an appropriate response for those who participate in workplace mobbing activities.

As a summary, some of the best practices or policies/recommendations for effectively dealing with workplace mobbing can include the following:

1. Remain watchful of any potential workplace mobbing encounters or behaviors.

2. Immediately address any unprofessional and inappropriate behaviors.

3. Keep detailed records and documentation of such cases; escalate and follow up accordingly.

4. Routinely remind everyone of the organization's expectations for all employees and supplement it with written manuals, training sessions, and signed agreements by both the employee and organizational managers.

5. Maintain open-door and confidentiality policies.

6. Practice having an unbiased attitude and disposition in the workplace.

7. Know your expert or designated HR professionals when coaching is needed.

8. Maintain an inclusive workplace for all.

Managers and HR professionals should seek to eliminate workplace mobbing proactively and reactively. Similar to preventing sexual harassment in the workplace, it is best to establish mandatory training for all managers and associates to create awareness and intolerance for bullying. There should be a hotline or some other anonymous channel to report suspected or experienced bullying. Guidelines should be well known and documented. Discipline should be quick, fair, and progressive to enforce the zero-tolerance policy for workplace mobbing.

It should be noted that the ineffectiveness of management in handling workplace mobbing incidents results in reduced reporting of harassment, along with more bullying and workplace mobbing behaviors. If employees believe they will not be treated fairly, the incident will not be reported, the issue will not be resolved, and they are less likely to report it and more likely to quit (O'Brien, 2019). If HR and management are effective in investigating and resolving issues of harassment, bullying and workplace mobbing, perpetrators would be less likely to participate for fear of disciplinary action.

\section{The Role of HR in Creating a Safe Work Environment}

Workplace mobbing, like bullying and all other forms of harrassment, are a serious problem in any organization. Its prevalence is influenced by the way an organization is structured, how effective management is at investigating reports, the personality of the individuals in the organization, and the overall organizational culture. Mobbing differs from bullying in that it involves a group of people that systematically target and abuse an individual, often with expulsion being the end goal. It has serious phychological and sometimes physical effects on the individual and can lead to workplace violence or suicide. Organizations that fail to effectively handle and elimate mobbing can face reduced productivity, low morale, a bad reputation, legal and financial consequences. Managers and HR have a responsibility to create a safe work environment by creating policies against harassment, consequences for improper behaviors, and properly investigating reports of mobbing.

The Society for Human Resources Management (SHRM) recommends certain steps for investigating and preparing harassment reports that create a fair and just system. The recommendations are to ensure confidentiality, provide interim protection, select an investigator that is objective, remain unbiased and neutral with no stake in the outcome, create a plan for the investigation, develop interview questions for the investigation, conduct interviews, make a decision, close the investigation, and develop a written summary of the investigation results.

In order to combat the negative effects of workplace mobbing, it is important to actively address it before it undermines the organizational diversity goals and irrevocably harms women, people of color, and those seen as "different" from the norm (Murrell, 2018). Management must recognize the types of environments where 
workplace mobbing might increase, such as in highly competitive workplaces with limited resources (Murrell, 2018). Thus, it is especially important that management strategies do not pit employees against each other and that there are efforts to facilitate inclusive workplaces with collaboration and balance between groups. Finally, when observing workplace mobbing, it is important to understand the reasons behind it and what changes can be made to stifle the possibility of similar actions in the future.

When there are cases of harassment, mobbing, or bullying in the workplace, companies can run into legal issues with some of the employees, especially if the victim is targeted based on gender, race, disability, religion, age, and other such protected categories (Cavico, Mujtaba, and Muffler, 2016; Mujtaba, 2010). Lawsuit settlements or defense of legal claims can get expensive and further hurt an organization (Kokemuller, 2016; Cavico and Mujtaba, 2014). The human resources department is morally, legally, and formally tasked with the responsibility of hiring, compensating, training, developing, monitoring, retiring, coaching / counseling, and creating a healthy work environment for all of its workforce (Liu, Gong, Zhou, and Huang, 2017). As such, human resources professionals must play a particularly important role in the strategic planning and implementation of proper policies for the organization.

Human resources professionals have an important role to play in making sure a workplace is free of bullying. The College and University Professional Association for Human Resources (CUPA-HR, 2017) outlines four strategies for preventing workplace mobbing. First, an organization needs to adopt a clear anti-bullying and anti-harassment policy. Bullying and harassment need to be officially defined within the organization, and a zero-tolerance policy should be implemented. In addition, a clear procedure for filing complaints needs to be provided to all employees. Employees should be trained annually to explain the different types of harassment, and to make the complaint procedure clear and easy to follow. Additionally, managers and supervisors should be trained separately from employees, as the issues they face are different; also, sometime employees cannot discuss some issues when their bosses are present. Lastly, the workplace should be monitored periodically to ensure that employees are not isolated and that they are not experiencing any forms of harassment (CUPAHR, 2017).

HR professionals are often tasked with the job of weighing the pros and cons of terminating employees who are not performing well and those who are bullying and harassing others. It has been said that, "the HRM function must 'surgically' reduce the workforce by quickly and effectively terminating the workers who are less valuable in their performance and those who violate workplace norms" (Noe et al., 2018: 96).

The HR department plays a very prominent leadership and management role when it comes to managing workplace mobbing. HR should be heavily included in the strategic planning, implementation and overall supervision of creating relevant policies and enforcing the rules. HR staff members have the responsibility of planning, executing and managing any mobbing cases to align with the business needs and to avoid the negative consequences. Every step of the way, HR should be involved in the pre-planning, initiations, announcement, implementation, supervision, and the after effects of relevant policies.

HR can play a vital leadership role in various functions of an organization, especially in terminating employees who are violating the company norms. Therefore, according to experts (Uhlig, 2017), it is HR's responsibility to:

1. Review the termination decision - HR's first responsibility should be to identify the specific problems that termination is to solve, and then assess the resources that can be devoted to it. In addition, HR must consider how the firing will affect the company in the longer term.

2. Explore alternatives - It is HR's responsibility to explore all the available alternatives so that decision makers have all the facts needed to make the best possible judgement.

3. Present those alternatives to decision makers - It is HR's responsibility to provide decision makers with a detailed report highlighting their recommendations as well as the applicable benefits and implications of the decision.

4. Plan the termination process - Professionals should work with executives and managers to establish and document the criteria for deciding which employee(s) should be terminated based on a fair process consider critical skills as well as job performance.

5. Manage the process - HR professional must have supervision responsibilities for the termination process and should keep relevant employees in the loop. HR must explain the reasons and the anticipated effects of the termination, while maintaining law and order. 
6. Develop various strategies that will help remaining employees to cope after the termination process is complete - Terminating an employee can cause poor morale, high levels of stress and even guilt among the remaining employees. HR professional should implement measures to instill confidence that the company and its employees will ultimately benefit from the change (Uhlig, 2017).

Research indicates that surviving employees suffer the negative effects of terminations just as profoundly as those who are terminated (Baruch and Hind, 2000). Survivor syndrome is the emotional and attitudinal characteristics of those employees who have survived (Mossholder et al., 2000). Research has shown that survivors exhibit a plethora of problems, such as de-motivation, cynicism, insecurity, demoralization, and a significant decline in organizational commitment (Baruch and Hind, 2000). The emotional after-effects of fear, anger, frustration, anxiety, and mistrust on the part of the survivors pose a real threat to performance and productivity as a smaller workforce is expected to perform an increasing number of responsibilities.

Overall, let us emphasize that managers and leaders are responsible to make sure employees are acting as adults and in a professional way in the workplace. It is the responsibility of any leader to take action if there is any evidence that an employee is a victim of workplace mobbing. Human resources should have an employee complaint process or form available for issues and grievances that arise in the workplace (Lowe, 2017). If an employee lodges a complaint, or it is brought to human resources or a manager's attention that workplace mobbing is occurring, then it is their responsibility to follow up and effectively deal with the issue in a timely manner. The immediate managers and HR professionals can also educate employees on the impact of workplace mobbing and how to avoid these situations.

Human resources staff and manager should be able to recognize the danger that mobbing poses to employees and their departments. Putting anti-bullying policies in place as well as processes that treat victims as valued employees can go a long way. Another policy to put into effect is rewarding employees who bring safety concerns or any such problems to the manager's attention. It can also be beneficial to make sure all performance measurement systems are fair, equitable, and objective for every employee.

\section{Summary}

Workplace mobbing can come in many forms such as oral or verbal aggression, stonewalling, exclusion, gossip, slander, and physical aggression. Victims of workplace mobbing report a range of physical and psychological symptoms that can include headaches, pain, depression, and anxiety. If mobbing becomes acceptable in the workplace, other employees may fear that they could be a target as well. This fear can lead to performance problems and anxiety. Employees could even see that their work environment is toxic and look for other places of employment. Businesses that allow workplace mobbing will eventually lose their best employees. Performance can also drop which will cause the business to lose money. In some cases, the business could face a lawsuit from victims if managers and leaders failed to properly address incidents of mobbing in a timely and effective manner.

If public and private sector organizations want to succeed in today's volatile global economy in a sustainable manner, they must be prepared to do business all around the world by effectively managing interpersonal conflicts and eliminating workplace mobbing. If an organization's operation spans the globe, it needs managers who can eliminate workplace mobbing by possessing a set of global management skills and attributes that will be beneficial to the organization in order to work across regional, national, and international boundaries to steer the business forward.

Human resource professionals must have policies in place for both managers and employees to train them in noticing suspicious bullying behaviors. They should also have policies in place that require employees to uphold professionalism within the workplace to maintain a healthy office culture. They must develop guidelines, create restrictions, and enforce penalties on behaviors that are detrimental to the company and its associates. It is their responsibility to create awareness that mobbing and bullying behaviors will not be tolerated. Ultimately, departmental managers and HR professionals are responsible for maintaining the dignity of their employees throughout their departments and organization by providing an inclusive and respectful work culture for all their workers.

\section{Acknowledgement}

Special thanks go to my graduate HR students during 2019 for their insights, personal examples, and research on this topic and to my colleagues for sharing their thoughts and experiences regarding mobbing and bullying in the modern workplace. 


\section{References}

1. Ågotnes, K. W., Einarsen, S. V., Hetland, J., \& Skogstad, A. (2018). The moderating effect of laissez-faire leadership on the relationship between co-worker conflicts and new cases of workplace bullying: A true prospective design. Human Resource Management Journal, 28(4), 555-568. Link: https://doiorg.ezproxylocal.library.nova.edu/10.1111/1748-8583.12200.

2. Appelbaum, S. H., Semerjian, G. \& Mohan, K. (2012). Workplace bullying: consequences, causes and controls (part two). Industrial and Commercial Training, 44(6), 337-344. DOI:10.1108/00197851211254770.

3. Appelbaum, S. H., Delage, C., Labib, N., and Gault, G. (1997). The survivor syndrome: Aftermath of downsizing. Career Development International, 2(6), 278-286. DOI:10.1108/13620439710178639.

4. Baillien, E., Camps, J., Van den Broeck, A., Stouten, J., Godderis, L., Sercu, M., \& De Witte, H. (2016). An eye for an eye will make the whole world blind: Conflict escalation into workplace bullying and the role of distributive conflict behavior. Journal of Business Ethics, 137(2), 415-429. Link: https://doiorg.ezproxylocal.library.nova.edu/10.1007/s10551-015-2563-y.

5. Baruch Y. and Hind P. (2000). 'Survivor syndrome' - a management myth? Journal of Managerial Psychology, 15, 29-45. DOI: https://doi.org/10.1108/02683940010305289.

6. Cavico, F. J., Mujtaba, B. G., Lawrence, E. T., and Muffler, S. (2018). Examining the Efficacy of the Common Law Tort of Intentional Infliction of Emotional Distress and Bullying in the Context of the Employment Relationship. Business Ethics and Leadership, 2(2), 14-31.

Link: http://armgpublishing.sumdu.edu.ua/journals/bel/volume-2-issue-2/article-2/.

7. Cavico, F. J., Mujtaba, B.G., and Muffler, S. (Spring 2016). Covenant-Not-To-Compete: The Relationship of Training and Education Criteria to Enforceability. SAM Advanced Management Journal, 81(2), 45-59. Link: https://www.questia.com/library/journal/1G1-460761250/covenants-not-to-compete-the-relationship-oftraining.

8. Cavico, F. J. and Mujtaba, B. G. (2020). Business Law for the Entrepreneur and Manager (4 $4^{\text {th }}$ edition). ILEAD Academy. Florida. Link: https://www.amazon.com/Business-Entrepreneur-Manager-FrankCavico/dp/1936237172/ref=sr_1_1?dchild=1\&keywords=Frank+Cavico\&qid=1585923668\&sr=8-1.

9. Comaford, C. (2016, September 20). 75\% Of Workers Are Affected By Bullying - Here's What To Do About It. Retrieved January 12, 2020 from: https://www.forbes.com/sites/christinecomaford/2016/08/27/theenormous-toll-workplace-bullying-takes-on-your-bottom-line/\#38cba9d45595.

10.CUPA-HR (2017). HR's Role in Managing Bullying and Harassment at Work. Available at: https://www.cupahr.org/blog/hrs-role-in-managing-bullying-and-harassment-at-work/.

11.Datta, D. K., Guthrie, J. P., Basuil, D., and Pandey, A. (2010). Causes and Effects of Employee Downsizing: A Review and Synthesis. Journal of Management, 36(1), 281-348. DOI:10.1177/0149206309346735.

12.Dalton, M. (1948). The Industrial "Rate Buster": A Characterization. Human Organization, 7(1), 5-18. DOI: 10.17730/humo.7.1.f461ht3145154752.

13.Davenport, N., Distler Schwartz, R. \& Pursell Elliott, G. (1999). Mobbing: Emotional Abuse in the American Workplace. Iowa: Civil Society Publishing. http://aleph.unisg.ch/hsgscan/hm00019761.pdf.

14.De Cieri, H., Sheehan, C., Donohue, R., Shea, T., \& Cooper, B. (2019). Workplace bullying: an examination of power and perpetrators. Personnel Review, 48(2), 324-341. Link: https://doiorg.ezproxylocal.library.nova.edu/10.1108/PR-02-2018-0057.

15.Duffy, M., \& Sperry, L. (2012). Mobbing: Causes, consequences, and solutions. Retrieved from https://ebookcentral.proquest.com.

16.Duffy, M. \& Sperry, L. (2013). Overcoming Mobbing: A Recovery Guide for Workplace Aggression and Bullying. USA: Oxford University Press. https://www.bookdepository.com/Overcoming-MobbingMaureen-Duffy-Len-Sperry/9780199929559.

17.Fader, S. (2018, January 23). Are You Suffering From Workplace Mobbing? Here's How To Handle It. Retrieved November 30, 2019, from: https://www.betterhelp.com/advice/behavior/are-you-suffering-fromworkplace-mobbing-heres-how-to-handle-it/.

18.Georgakopoulos, A. \& Kelly, M. P. (2017). Tackling workplace bullying. International Journal of Workplace Health Management, 10(6), 450-474. DOI: 10.1108/ijwhm-11-2016-0081.

19.Gleason, M. (2017, December 13). HR's Role in Managing Bullying and Harassment at Work. Retrieved from https://www.cupahr.org/blog/hrs-role-in-managing-bullying-and-harassment-at-work/.

20.Gordon, S. (2019, November 19). How Workplace Bullies Pick Their Targets. Retrieved from: https://www.verywellmind.com/reasons-why-workplace-bullies-target-people-460783.

21.Gordon, S. (2019). The Effects of Workplace Bullying. Retrieved from: https://www.verywellmind.com/whatare-the-effects-of-workplace-bullying-460628. 
22.Hamblen, K. (2018, July 24). Mobbing in the Workplace. Retrieved from https://www.legalmatch.com/lawlibrary/article/mobbing-in-the-workplace.html.

23.Hamblen, K. (2018). What is Mobbing in the Workplace? LegalMatch. Available at: https://www.legalmatch.com/law-library/article/mobbing-in-the-workplace.html.

24.Heathfield, S. M. (2019). Here Is a Look at the Effects of Downsizing on Surviving Employees. January 5, 2019 from: https://www.thebalancecareers.com/how-employees-respond-to-change-after-layoffs-1918585.

25.Henshaw, S. (2018, July 8). Bullying at Work: Workplace Mobbing is on the Rise. Retrieved from https://psychcentral.com/blog/bullying-at-work-workplace-mobbing-is-on-the-rise/.

26. Hirsch, A. (2010, January 4). Bullying in the workplace on the rise. Retrieved from: https://www.theguardian.com/money/2010/jan/04/bullying-workplace-recession.

27.How to Prevent Bullying \& Mobbing in the Workplace? (February 7, 2017). Formaspace.com. Link: https://formaspace.com/articles/workplace-bulletin/prevent-bullying-mobbing-in-the-workplace/.

28.Huang, J. L., Ryan, A. M., and Mujtaba, B. G. (2015). Vicarious experience of justice: when unfair treatment of one's colleague matters. Personnel Review, 44(6), 826-846. Link: https://www.emerald.com/insight/content/doi/10.1108/PR-02-2013-0026/full/html.

29.Kyaw, A.M.M., Harland, P., and Mujtaba, B.G. (June 2017). Global Management Skills and Attributes for International Business. Journal of International Relations and Foreign Policy, 5(1), 1-16. Link: http://jirfp.com.com/current-jirfp.

30.Kurebwa, J. (2011). Organisational downsizing and its impact on leavers and survivors: The case of the reserve Bank of Zimbabwe. Journal of Emerging Trends in Economic and Management Sciences, 2(4), 264-269. Link: https://journals.co.za/content/sl_jetems/2/4/EJC134340.

31.Latack, J. C., Kinicki, A. J., and Prussia, G. E. (1995). An integrative process model of coping with job loss. Academy of Management Review, 20, 311-335. Link: https://doi.org/10.5465/amr.1995.9507312921.

32.Lowe, J. (2017, November 28). How Should HR Handle Workplace Bullying?: LaborSoft. Retrieved from: https://www.laborsoft.com/blog/how-should-hr-handle-workplace-bullying.

33.Maran, D. A., Bernardelli, S., \& Varetto, A. (2018, January). Mobbing (bullying at work) in Italy: characteristics of successful court cases. Retrieved November 30, 2019, from: https://www.ncbi.nlm.nih.gov/pubmed/29187725.

34.McLaughlin, K. (2014). Viewpoint workplace bullying: A silent epidemic. Society of Human Resource Management. Retrieved from https://www.shrm.org.

35.Morrison Kenney, R. (2014). Mobbing in the Context of a Woman's Life. Workplace, 24, 42-51. Retrieved on November 30, 2019 from:

http://eds.b.ebscohost.com.ezproxylocal.library.nova.edu/eds/pdfviewer/pdfviewer?vid=43\&sid=c8294b9 5-7f1d-48c7-bc23-df3effac0603\%40pdc-v-sessmgr05.

36.Mossholder, K.W., Settoon, R.P., Armenakis, A.A., and Harris, S.G. (2000). Emotion during organizational transformations. An interactive model of survivor reactions. Group and Organization Management, 25, 220-243. DOI: $10.1177 / 1059601100253002$.

37.Mujtaba, B. G. (2014). Managerial Skills and Practices for Global Leadership. ILEAD Academy: Davie, Florida. https://www.amazon.com/Managerial-Skills-Practices-Global-Leadership/dp/1936237067.

38.Mujtaba, B. G. (2010). Workforce Diversity Management: Challenges, Competencies and Strategies ( $2^{\text {nd }}$ edition). ILEAD Academy: Florida. https://nsuworks.nova.edu/hcbe_facbooks/93/.

39.Mujtaba, B. G., Cavico, F. J., and Senathip, T. (2020). Strategies for Personal, Organizational and Professional Leadership Success. Scientific Journal of Research \& Reviews, 2(3), 1-10. DOI:10.33552/SJRR.2020.02.000538. Link: https://irispublishers.com/sjrr/volume2-issue3.php.

40. Mujtaba, B. G., Ping, H., and Jieqiong, C. (2013). A Cross-cultural Analysis of Management Skills with Chinese, Iranian, Pakistanis, Thai, and American Managers. SAM Advanced Management Journal, 78(1), 50-67. Link: https://search.proquest.com/openview/dffef1a721ae6361d27b9561ea22b420/1?pqorigsite $=$ gscholar\&cbl $=40946$.

41.Mujtaba, B. G. and McCartney, T. (2010). Managing Workplace Stress and Conflict amid Change, $2^{\text {nd }}$ edition. ILEAD Academy; Florida. Link: https://www.amazon.com/Managing-Workplace-Stress-ConflictChange/dp/0977421163/ref=sr_1_2?dchild=1\&keywords=Managing+Workplace+Stress+and+Conflict+a mid+Change\&qid $=1585923847 \& s r=8-2$.

42.Murell, Audrey (August 27, 2018). When Top Performers are Bullied Inclusive Organizations Suffer. Forbes.com. Link: https://www.forbes.com/sites/audreymurrell/2018/08/27/when-top-performers-arebullied-inclusive-organizations-suffer/\#67a0e93197b4.

43.Noe, R. A., Hollenbeck, J. R., Gerhart, B. \& Wright, P. M. (2018). Human Resource Management: Gaining a Competitive Advantage ( $11^{\text {th }}$ Ed.). New York: McGraw-Hill. Link: 
https://www.amazon.com/Fundamentals-Human-Resource-Management-

Analytics/dp/154437772X/ref=redir_mobile_desktop?ie=UTF8\&aaxitk=YcValNwPT-

tdi9YJZNDj9Q\&hsa_cr_id=1286144410901\&ref_=sb_s_sparkle.

44.O'Brien, M. (2019). Here's Why So Many Workplace Issues Go Unreported. Retrieved from: https://hrexecutive.com/heres-why-so-many-workplace-issues-go-unreported/.

45.Petersen, Lainie (January 24, 2019) What Is Mobbing at the Workplace? Chron.com. Link: https://smallbusiness.chron.com/mobbing-workplace-43426.html.

46.Petzall, B. J., Parker, P. E., and Stoeberl, P. (2000). Another side to downsizing: survivors' behavior and self-affirmation. Journal of Business Psychology, 14, 593-603. https://doi.org/10.1023/A:1022990214073.

47.Powers, J. L, Brotheridge, C. M, Blenkinsopp, J., Bowes-Sperry. L., Bozionelos, N., Buzady, Z., Chuang, A., Drnevich, D., Garzon-Vico, A., Leighton, C., Madero, S. M., Mak, W., Mathew, R., Monserrat, S. I., Mujtaba, B. G., Olivas-Lujan, M. R., Polychroniou, P., Sprigg, C. A., Axtell, C., Holman, D. Ruiz-Gutierrez, J.A., and Obiajulu Nnedum, A. U. (2013). Acceptability of workplace bullying: A comparative study on six continents. Journal of Business Research, 66(1), 374-380. Link: https://www.sciencedirect.com/science/article/pii/S0148296311002955?via\%3Dihub.

48.Ramlall, S. J., Al-Sabaan, S., and Magbool, S. (2014). Layoffs, Coping, and Commitment: Impact of Layoffs on Employees and Strategies Used in Coping with Layoffs. Journal of Management and Strategy, 5(2), 25-30. DOI:10.5430/jms.v5n2p25.

49.Robinson, B. (2019, October 11). New Study Says Workplace Bullying on Rise: What You Can Do During National Bullying Prevention Month. Retrieved from:

https://www.forbes.com/sites/bryanrobinson/2019/10/11/new-study-says-workplacebullying-on-risewhat-can-you-do-during-national-bullying-preventionmonth/\#76ae291b2a0d.

50.Saltmarsh, M. (2007, February 5). The Workplace: It's called mobbing - Business - International Herald Tribune. Retrieved January 13, 2020 from:

https://www.nytimes.com/2007/02/05/business/worldbusiness/05iht-workcol06.4474372.html.

51.Sarwar, A., Khan, M. M., and Mujtaba, B. G. (2018). Managing Despotic Leadership, Workplace Ostracism and Knowledge Hoarding: a Serial Mediation Model. Advanced Management Journal, 82(4), 4-19. Link: https://www.questia.com/library/journal/1G1-567547340/despotic-leadership-workplace-ostracism-andknowledge.

52.Schmitt, A., Borzillo, S. and Probst, G. (2012). Don't let knowledge walk away: Knowledge retention during employee downsizing. Management Learning, 43(1), 53-74. Link: https://doi.org/10.1177/1350507611411630.

53.Segal, L. (2017, December 5). The Injury of Mobbing in the Workplace. Retrieved from: https://conflictremedy.com/the-injury-of-mobbing-in-the-workplace/.

54.Seidel, M. (2019, January 24). Smallbusiness.Chron.com. What is mobbing at the workforce. Retrieved December 29, 2019 from: https://smallbusiness.chron.com/mobbing-workplace-43426.html.

55.Senathip, T., Mujtaba, B. G., and Cavico, F. J. (2017). Policy-Making Considerations for Ethical and Sustainable Economic Development. Economy, 4(1), 7-14.

DOI: https://doi.org/10.20448/journal.502.2017.41.7.14.

56.Sheenan, M. (2004). Workplace Mobbing: a proactive response. Department of Management - Griffith University 2004. Retrieved from: http://citeseerx.ist.psu.edu/viewdoc/download?doi=10.1.1.588.6134\&rep=rep1\&type=pdf.

57.Shelton, T. L. (2011). Mobbing, Byllying, and Harassment: A Silent Dilemma in the Workplace. Research Papers, 149. Masters of Science: Southern Illinois University Carbondale. Link: 49. http://opensiuc.lib.siu.edu/gs_rp/149.

58.Sperry, M. D. (2012). Mobbing: Causes, Consequences \& Solutions . Oxford University Press. Available at: https://www.oxfordscholarship.com/view/10.1093/acprof:oso/9780195380019.001.0001/acprof9780195380019.

59.Sungwan, Patcharin, Deoisres, Wannee and Chaimongkol, Nuijjaree (2017). Perceptions of Newly Registered Thai Nurses about Workplace Bullying. Thai Pharm Health Science Journal, 12(3), 101-107. Link: https://www.semanticscholar.org/paper/Perceptions-of-Newly-Registered-Thai-Nurses-about-SungwanDeoisres/ab23bbaf172fc94f3d21d8a5773b7bc18911febf.

60.Travaglione, A. and Cross, B. (2006). Diminishing the social network in organizations: Does there need to be such a phenomenon as 'survivor syndrome' after downsizing? Strategic Change, 15(1), 1-13. Link: https://espace.curtin.edu.au/handle/20.500.11937/21041. 
61.Uhlig, D. K. (November 21, 2017). How Does Downsizing impact the Role of Human Resource Management? Retrieved January 15, 2019 from: https://smallbusiness.chron.com/downsizing-impact-rolehuman-resource-management-38669.html.

62.Vandekerckhove, W. \& Commers, M. R. (2003). Downward Workplace Mobbing: A Sign of the Times? Journal of Business Ethics, 45(1), 41-50. Link: https://doi.org/10.1023/A:1024168311652.

63.Vartia, M. (1996). The sources of bullying - psychological work environment and organizational climate. European Journal of Work and Organizational Psychology, 5(2), 203-214. Link: https://scholar.google.com/scholar?q=The+sources+of+bullying+psychological+work+environment+and+organizational+climate\&hl=fr\&as_sdt=0\&as_vis=1\&oi=scholart.

64.Wall, A. E., Smith, R. A., \& Nodoushani, O. (2018). Bullying in the workplace: The great balancing act of victim rights and organizational policies. Journal of Competitiveness Studies, 26(1/2), 107-123. Retrieved from:

http://search.ebscohost.com.ezproxylocal.library.nova.edu/login.aspx?direct=true \&db=buh\&AN=134705 $454 \&$ site $=$ ehost-live.

65.Workplace Bullying Institute (2019). The WBI definition of workplace mobbing. Retrieved from https://www.workplacebullying.org/individuals/problem/being-bullied/.

66.Yamada, M. D. and Duffy, M. (2018). Workplace Bullying and Mobbing in The United States. Praeger Publishers Inc: US. Link: https://www.amazon.fr/Workplace-Bullying-Mobbing-UnitedStates/dp/1440850232.

67.Zachariadou, T., Zannetos, S., Chira, S. E., Gregoriou, S., \& Pavlakis, A. (2017, December 5). Prevalence and Forms of Workplace Bullying Among Health-care Professionals in Cyprus: Greek Version of "Leymann Inventory of Psychological Terror" Instrument. Retrieved November 28, 2019, from https://www.sciencedirect.com/science/article/pii/S2093791116301433. 